\title{
Sistemas de manejo e atributos físico-hídricos de um Latossolo Vermelho cultivado com milho
}

\author{
Karina de V. Rossetti ${ }^{1}$ \& José F. Centurion ${ }^{1}$
}

\section{RESUMO}

Neste trabalho objetivou-se avaliar os atributos físico-hídricos de um Latossolo Vermelho de Jaboticabal, SP, sob sistemas de uso e tempos de adoção de manejos cultivado com milho. O delineamento experimental foi inteiramente casualizado, em parcelas subdivididas, com seis repetições e os tratamentos foram: sistema plantio direto por 6 anos (SPD6), sistema plantio direto por 8 anos (SPD8), sistema plantio direto por 10 anos (SPD10), sistema de preparo convencional (SPC) e uma área adjacente de mata nativa (MN). Avaliaram-se resistência mecânica do solo à penetração (RP), densidade, macroporosidade, microporosidade do solo nas camadas de $0-0,05 ; 0,05-0,10$ e $0,10-0,20 \mathrm{~m}$ e condutividade hidráulica saturada (K $\theta$ ) a $0,15 \mathrm{~m}$ de profundidade. Verificou-se que as condições da RP foram favoráveis ao cultivo até $0,20 \mathrm{~m}$ indicando uma estrutura preservada, mesmo após a escarificação do solo. Além disso, A K $\theta$ no solo mostrou comportamento semelhante entre o SPC e o SPD nos tempos de adoção, embora este tenha apresentado, em uma parte do ciclo do milho, valores de macroporosidade próximos de $0,10 \mathrm{~m}^{3} \mathrm{~m}^{-3} \mathrm{e}$ tensões de água no solo próximas a 0,09 MPa.

Palavras-chave: resistência do solo à penetração, aeração do solo, Zea mays

\section{Tillage systems and hydro-physical attributes of an Oxisol cultivated with maize}

\begin{abstract}
The purpose of this experiment was to evaluate the hydro-physical attributes of the Red Oxisol cultivated with maize in Jaboticabal, São Paulo State, Brazil, under different systems of use and periods of adoption of managements. The experiment was arranged in a completely randomized design with split-plot arrangement, with six replications and the treatments were: six years of no-tillage system (SPD6), eight years of no-tillage system (SPD8), ten years of no-tillage system (SPD10), conventional tillage system (SPC) and an adjacent area of native forest (NF). The soil penetration resistance (PR), density, macroporosity, microporosity of the soil in layers of $0-0.05 ; 0.05-0.10$ and $0.10-0.20 \mathrm{~m}$, and the saturated hydraulic conductivity $(\mathrm{K} \theta)$ in 0.15 $\mathrm{m}$ depth were evaluated. It was found that the PR conditions were favorable for the cultivation to $0.20 \mathrm{~m}$, indicating a structure preserved even after soil chiseling. Furthermore, the $K \theta$ in the soil showed similar behavior between SPC and periods of SPD, although this was shown in a part of maize cycle, macroporosity values near $0.10 \mathrm{~m}^{3} \mathrm{~m}^{-3}$ and soil water tensions near $0.09 \mathrm{MPa}$.
\end{abstract}

Key words: resistance to penetration, soil aeration, Zea mays 


\section{INTRODUÇÃO}

A diversificação dos sistemas de manejo do solo possui a finalidade de minimizar os efeitos da degradação da sua estrutura, que ocorrem por meio da compactação e da restrição à infiltração de água, os quais podem comprometer o desenvolvimento do sistema radicular das plantas. Sabendose, porém, que o cultivo inadequado do solo altera os atributos físicos em relação ao solo não cultivado, surge a necessidade de se quantificar e qualificar as condições estruturais do solo para, desta forma, obter informações sobre a eficácia do manejo do solo e suas influências na produtividade da cultura agrícola.

Cientes de que as pressões acumulativas exercidas pelas máquinas e implementos podem causar um rearranjo dos componentes sólidos do solo, desestruturando-o e o compactando, diminuindo principalmente a macroporosidade (Dexter et al., 2007). Machado et al. (2008) verificaram, trabalhando num Latossolo Vermelho, que a mudança do uso do solo por mais de 20 anos de mata para pousio e cultivo (culturas anuais com preparo convencional do solo) aumentou a densidade do solo. Os sistemas de preparo convencional e plantio direto aumentam a densidade e reduzem a porosidade total, a microporosidade, a retenção e a disponibilidade de água em relação ao campo e à mata nativa em Argissolo Vermelho (Flores et al., 2008). Assim, Torres et al. (2011) observaram, em Latossolo Vermelho, que apenas no campo nativo não ocorreram valores maiores que $2 \mathrm{MPa}$ de resistência mecânica do solo à penetração (RP) em comparação com os sistemas de manejo, valor este considerado crítico, segundo Tormena et al. (1998) em Latossolo Roxo porém ele depende de atributos, como a condição estrutural do solo e a cultura em estudo. Neste aspecto, Freddi et al. (2006) observaram que valores entre 0,90 a 2,00 MPa em Latossolo Vermelho de textura argilosa não diminuíram a produtividade do milho. Tendo em vista que a RP depende da condição física do solo e do tipo de cultura, o monitoramento (Tavares Filho \& Ribon, 2008), associado à umidade do solo (Souza et al., 2006) durante todo o ciclo da cultura se constitui em uma estratégia fundamental.

A condutividade hidráulica é uma das propriedades do solo que melhor indicam as diferenças estruturais entre as diversas camadas que constituem o perfil. Segundo Reichardt \& Timm (2012), a condutividade hidráulica depende do espaço poroso, varia muito de solo para solo e mesmo dentro da mesma classe de solo. Neste sentido Castro et al. (2009) concluíram, em seu estudo, que 8 anos de semeadura direta em solo cultivado com milho permitiram maior condutividade hidráulica saturada de um Latossolo Vermelho quando comparado com os sistemas de preparo mecânico (preparo escarificado e preparo convencional) devido à maior continuidade dos poros.

As identificações da degradação e a melhoria dos manejos sustentáveis do solo são importantes e, em assim sendo, sugerem a necessidade de mais estudos. Desta forma, o objetivo deste trabalho foi avaliar os atributos físico-hídricos de um Latossolo Vermelho sob sistemas de uso e tempos de adoção de manejos cultivados com milho.

\section{Material e Métodos}

O experimento foi realizado em Jaboticabal, SP, situado nas coordenadas geográficas de $21^{\circ} 15^{\prime} 29^{\prime \prime}$ de latitude Sul, $48^{\circ} 16^{\prime}$ 47 " de latitude Oeste e altitude média de $614 \mathrm{~m}$. O clima da região, de acordo com a classificação climática de Köppen, é do tipo Cwa, com verão quente e inverno seco (Figura 1). O solo da área experimental foi classificado, de acordo com Andrioli \& Centurion (1999) em Latossolo Vermelho distrófico típico, argiloso, A moderado, caulinítico, hipoférrico, muito profundo e com relevo plano a suave ondulado.

Antes da instalação do experimento o solo vinha sendo cultivado em sistema de preparo convencional, durante 30 anos, com sucessão anual de milho e soja, no verão, e safrinha de milho no outono. A partir dos anos 2000, 2002 e 2004, foram implantados o sistema plantio direto de dez anos (SPD10), o sistema plantio direto de oito anos (SPD8) e o sistema plantio direto de seis anos (SPD6) respectivamente. No ano agrícola 2008/09 as quatro partes da área, cada uma com $60 \mathrm{~m}^{2}$, foram destinadas ao sistema de preparo convencional (SPC) e as demais áreas dos sistemas de manejo, cada qual com $60 \mathrm{~m}^{2}$, também foram demarcadas. O SPC foi constituído de uma escarificação do solo até $0,30 \mathrm{~m}$ de profundidade seguida de uma gradagem leve. Em dezembro de 2009 foi realizada a semeadura do milho, híbrido Impacto da empresa Syngenta, por meio da semeadoraadubadora de precisão da marca Marchesan, modelo Cop Suprema equipada com 7 linhas espaçadas $0,90 \mathrm{~m}$, largura útil de $6,30 \mathrm{~m}$ e com profundidade média de semeadura de $0,03 \mathrm{~m}$.

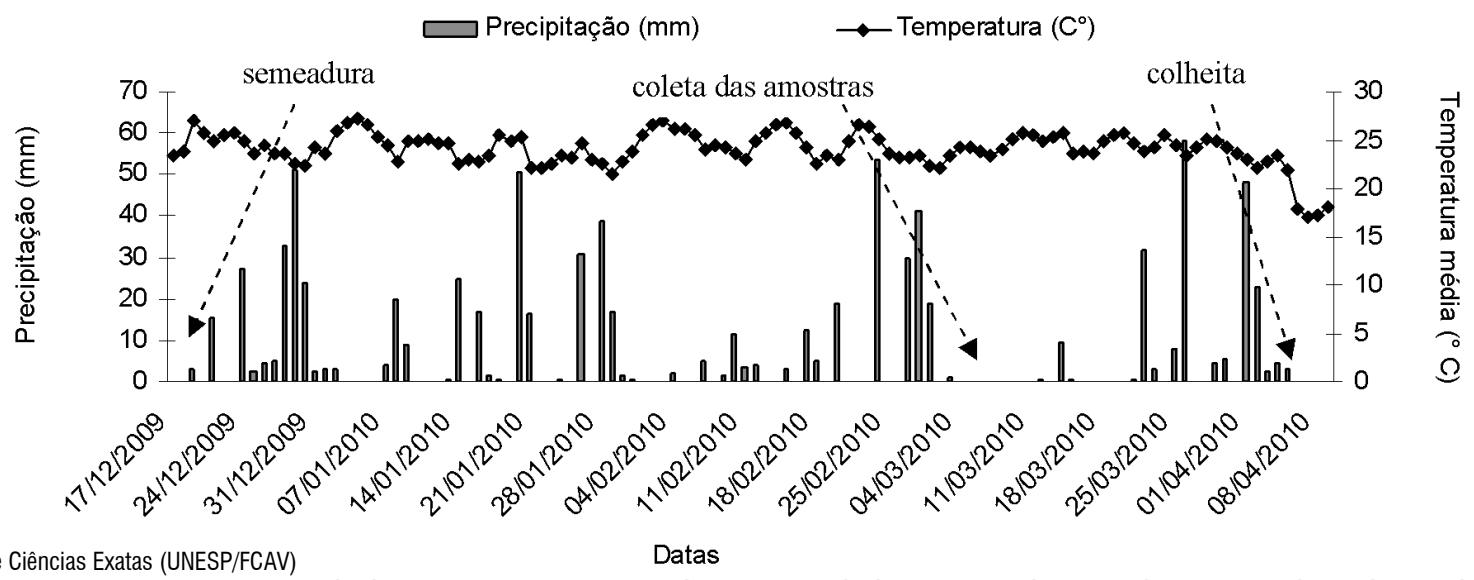

Fonte: Depto. de Ciências Exatas (UNESP/FCAV)

Datas

Figura 1. Precipitação acumulada e temperatura média semanal durante o desenvolvimento da cultura do milho $(2009 / 10)$ 
A análise química e a adubação do solo foram realizadas conforme Raij et al. (2001) (Tabela 1) em que a última consistiu da aplicação de $0,300 \mathrm{Mg} \mathrm{ha}^{-1}$ nas parcelas da formulação N-P-K (8-20-20), para obtenção da produtividade esperada de 7 a $9 \mathrm{Mg} \mathrm{ha}^{-1}$. A adubação de cobertura foi realizada no estádio

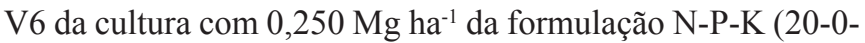
10) em superfície, ao lado da linha de plantio. Para o sistema plantio direto foi utilizado o sulcador de adubo tipo haste, para o sistema de preparo convencional, discos duplos defasados com um trator Valtra BH 140, para tracionar a semeadora-adubadora.

Tabela 1. Características químicas do Latossolo Vermelho na camada de 0-0,20 m, antes da adubação

\begin{tabular}{|c|c|c|c|c|c|c|c|}
\hline $\mathrm{pH}\left(\mathrm{CaCl}_{2}\right)$ & $P$ & K & $\mathrm{Ca}$ & $\mathrm{Mg}$ & SB & CTC & $\bar{v}$ \\
\hline $1: 2,5$ & $\left(\mathrm{mg} \mathrm{dm}^{-3}\right)$ & & & $10 \mathrm{I}_{\mathrm{C}} \mathrm{dt}$ & & & (\%) \\
\hline 5,2 & 39 & 1,1 & 24 & 12 & 37 & 66 & 56 \\
\hline
\end{tabular}

O experimento foi conduzido em delineamento inteiramente casualizado e em parcelas subdivididas, com seis repetições. As parcelas foram constituídas pelos tratamentos (sistemas de uso e tempos de adoção de manejos) e as subparcelas pelas camadas de solo amostradas (0-0,05; 0,05-0,10 e 0,10-0,20 m).

A composição granulométrica dos solos foi determinada em amostras deformadas por meio da dispersão com $\mathrm{NaOH}$ $\left(0,1 \mathrm{~mol} \mathrm{~L}^{-1}\right)$ e agitação lenta durante $16 \mathrm{~h}$ sendo o conteúdo de argila obtido pelo método da pipeta (EMBRAPA, 1997). O Latossolo Vermelho apresentou valores médios de $330 \mathrm{~g} \mathrm{~kg}^{-1}$ de argila, $40 \mathrm{~g} \mathrm{~kg}^{-1}$ de silte e de $630 \mathrm{~g} \mathrm{~kg}^{-1}$ de areia total.

Como a RP varia inversamente ao conteúdo de água no solo, foi realizado seu monitoramento no campo e durante todo o ciclo do milho com frequência de duas vezes por semana, por meio de duas baterias de tensiômetros instalados nos tratamentos SPD6, SPD8, SPD10 e SPC sendo cada bateria composta por dois tensiômetros nas profundidades de $0,10 \mathrm{e}$ $0,20 \mathrm{~m}$.

Em onze de março de 2010 foram coletadas, em seis pontos aleatórios em cada tratamento, amostras indeformadas de solo na entrelinha do milho, com cilindros de 53,18 10 $\mathrm{m}^{3}(0,032 \mathrm{~m}$ de altura e $0,046 \mathrm{~m}$ de diâmetro) no ponto médio de cada camada, para determinação dos atributos físicos do solo. As amostras foram saturadas e submetidas às tensões de 0,$001 ; 0,006 ; 0,010 ; 0,033 ; 0,06$ e $0,1 \mathrm{MPa}$, em câmaras de Richards (Klute, 1986) e ao atingir o equilíbrio foram pesadas determinando-se a RP com duas repetições por amostra, na camada de 1 a $2 \mathrm{~cm}$, perfazendo 100 leituras por repetição, as quais foram utilizadas para obtenção da RP média de cada cilindro. A RP foi determinada por meio de um penetrômetro eletrônico estático com velocidade constante de penetração de $0,01 \mathrm{~m} \mathrm{~min}^{-1}$, cone com ângulo de $60^{\circ}$ e com área da base de
$2,9610^{-6} \mathrm{~m}^{2}$ equipado com atuador linear e célula de carga de $20 \mathrm{~kg}$ acoplada a um microcomputador para a aquisição dos dados realizando-se uma leitura de RP por segundo (Tormena et al., 1998). Na sequência, as amostras foram secas em estufa a $105^{\circ} \mathrm{C}$, durante $24 \mathrm{~h}$, para determinação do conteúdo de água pelo método gravimétrico, em cada tensão (EMBRAPA, 1997) e da densidade do solo (tensão de 0,010 MPa), (Blake \& Hartge, 1986).

A microporosidade do solo foi determinada por secagem, na tensão de 0,010 MPa, em câmara de Richards com placa porosa (Klute, 1986), a porosidade total segundo Danielson $\&$ Sutherland (1986) e a macroporosidade do solo obtida por diferença entre a porosidade total e a microporosidade.

Devido ao monitoramento da tensão de água no solo nos tratamentos SPD6, SPD8, SPD10 e SPC e por meio das equações ajustadas entre os valores médios do conteúdo de água e resistência mecânica do solo à penetração (Tabela 2), nas tensões de 0,$001 ; 0,006 ; 0,010 ; 0,033 ; 0,06$ e $0,1 \mathrm{MPa}$, foi possível estimar a variação da RP durante o experimento nesses tratamentos com base nas leituras dos tensiômetros nas camadas de 0-0,05 e 0,10-0,20 m, visto que o principal objetivo foi verificar este comportamento nas camadas superficiais e subsuperficiais do solo.

A condutividade hidráulica saturada do solo nos sistemas de manejo foi realizada em março de 2010, em quatro pontos por parcela, utilizando-se um permeâmetro (2800 KI Guelph Permeameter) instalado a $0,15 \mathrm{~m}$ de profundidade e submetido a duas cargas hidráulicas ( 0,03 e $0,06 \mathrm{~m}$ de coluna da água). As leituras foram realizadas por meio do nível da coluna de água presente no aparelho e a partir do momento da estabilização das leituras utilizou-se a média das três últimas e se calculou a condutividade hidráulica saturada $(\mathrm{K} \theta)$ de acordo com a Eq. 1:

$\mathrm{K} \Theta=\{[(0,0041)(32,29)(\mathrm{X} 1)]\}-\{[(0,0054)(35,39)(\mathrm{X} 2)]\} \mathrm{FC}$

em que:

X1 - média das três últimas leituras com carga hidráulica de $0,06 \mathrm{~m}$ de coluna de água, $\mathrm{cm} \mathrm{s}^{-1}$

X2 - média das três últimas leituras com carga hidráulica de $0,03 \mathrm{~m}$ de coluna de água, $\mathrm{cm} \mathrm{s}^{-1}$

FC - é o fator de conversão para $\mathrm{mm} \mathrm{h}^{-1}$

Em 8 de abril de 2010 foram medidos, no estádio R6 da cultura do milho, a altura das plantas, a altura de inserção da primeira espiga e o diâmetro do segundo internódio do colmo em seis plantas por parcela na área útil. A altura das plantas foi determinada entre o solo e a inserção da base do pendão enquanto o diâmetro do colmo foi determinado utilizando-se a média de duas leituras do segundo internódio do colmo por

Tabela 2. Regressão entre o conteúdo de água gravimétrico (UG) e a resistência mecânica à penetração de um Latossolo Vermelho (RP) para as camadas de 0-0,05 m e 0,10-0,20 m, em tratamentos durante o ciclo da cultura do milho

\begin{tabular}{|c|c|c|c|c|}
\hline \multirow{2}{*}{ Tratamentos } & \multicolumn{4}{|c|}{ Camadas (m) } \\
\hline & \multicolumn{2}{|c|}{$0-0,05$} & \multicolumn{2}{|c|}{$0,10-0,20$} \\
\hline SPD6 & $\mathrm{RP}=2,146 \mathrm{e}^{-6,08 \mathrm{UG}}$ & $R^{2}=0,61 ; p=0,08^{N S}$ & $R P=27,87 e^{-17,2 U G}$ & $\mathrm{R}^{2}=0,77 ; p=0,06^{\mathrm{NS}}$ \\
\hline SPD8 & $\mathrm{RP}=5,607 \mathrm{e}^{-7,77 \mathrm{UG}}$ & $R^{2}=0,79 ; p<0,05$ & $\mathrm{RP}=5,691 \mathrm{e}^{-7,95 \mathrm{UG}}$ & $R^{2}=0,86 ; p<0,01$ \\
\hline SPD10 & $\mathrm{RP}=3,12 \mathrm{e}^{-4,59 \mathrm{UG}}$ & $R^{2}=0,80 ; p<0,05$ & $\mathrm{RP}=6,580^{\mathrm{e}-7,49 \mathrm{UG}}$ & $R^{2}=0,80 ; p<0,05$ \\
\hline SPC & $\mathrm{RP}=2,623 \mathrm{e}^{-5,67 \cup G}$ & $R^{2}=0,69 ; p=0,09^{N S}$ & $\mathrm{RP}=5,993 \mathrm{e}^{-8,04 U G}$ & $\mathrm{R}^{2}=0,65 ; p=0,11^{\mathrm{NS}}$ \\
\hline
\end{tabular}

SPD6 - sistema plantio direto de 6 anos; SPD8 - sistema plantio direto de 8 anos; SPD10 - sistema plantio direto de 10 anos e SPC - sistema de preparo convencional. NS - não significativo 
meio do paquímetro digital. Obteve-se a produtividade de grãos de milho extrapolando-se a produção de grãos da área útil da parcela para um hectare considerando-se a umidade padrão de $13 \%$. As análises de regressão foram efetuadas para avaliar a relação entre a RP estimada na tensão da capacidade de campo, $0,010 \mathrm{MPa}$, para a camada de $0-0,20 \mathrm{~m}$ com base nas repetições da RP quantificadas nas três camadas avaliadas, totalizando 24 observações e as características das plantas (altura, diâmetro do colmo, inserção da primeira espiga e produtividade de milho) dos tempos de adoção de usos e manejos cultivados (SPD6, SPD8, SPD10 e SPC). Os resultados foram submetidos à ANOVA pelo software Assistat versão 7.5 beta e, quando este indicou diferença entre médias, utilizou-se o teste de Tukey $(\mathrm{p}<0,05)$.

\section{Resultados E Discussão}

Pela distribuição de poros do solo (Tabela 3) pode-se verificar que a menor macroporosidade ocorreu nos sistemas com plantio direto (SPD6, SPD8 e SPD10), nas camadas de 0-0,05 e 0,05-0,10 m em comparação com o SPC e a MN. De acordo com Silva et al. (2005b), normalmente o revolvimento do solo promove um aumento temporário da macroporosidade quando comparado ao plantio direto. Resultados semelhantes também foram observados por Albuquerque et al. (2001) ao constatarem que os macroporos decresceram da mata $\left(0,29 \mathrm{~m}^{3}\right.$ $\left.\mathrm{m}^{-3}\right)$ para o PC $\left(0,17 \mathrm{~m}^{3} \mathrm{~m}^{-3}\right)$ e deste para o PD6 $\left(0,13 \mathrm{~m}^{3} \mathrm{~m}^{-3}\right) \mathrm{e}$ as modificações verificadas no sistema plantio direto afetaram o crescimento e a produtividade da cultura do milho. Neste sentido, Silva et al. (2006) relataram, em Argissolo Vermelho, aumento da macroporosidade no preparo convencional quando comparado com o preparo reduzido e semeadura direta na

Tabela 3. Valores médios de macroporosidade, microporosidade e densidade do Latossolo Vermelho sob sistemas de uso e manejo, em camadas no cultivo do milho

\begin{tabular}{|c|c|c|c|c|c|}
\hline \multirow{2}{*}{$\begin{array}{c}\text { Camadas } \\
\text { (m) }\end{array}$} & \multicolumn{5}{|c|}{ Tratamentos } \\
\hline & MN & SPD6 & SPD8 & SPD10 & SPC \\
\hline & \multicolumn{5}{|c|}{ Macroporosidade $\left(\mathrm{m}^{3} \mathrm{~m}^{-3}\right)$} \\
\hline $0-0,05$ & $0,316 \mathrm{Aa}$ & $0,180 \mathrm{BCa}$ & $0,082 \mathrm{Da}$ & $0,117 \mathrm{CDa}$ & $0,267 \mathrm{Aa}$ \\
\hline $0,05-0,10$ & $0,234 \mathrm{Ab}$ & $0,103 \mathrm{Bb}$ & $0,124 \mathrm{Ba}$ & $0,081 \mathrm{Ba}$ & $0,224 \mathrm{Aa}$ \\
\hline $0,10-0,20$ & $0,145 \mathrm{Ac}$ & $0,106 \mathrm{Ab}$ & $0,141 \mathrm{Aa}$ & $0,061 \mathrm{Aa}$ & $0,149 \mathrm{Ab}$ \\
\hline \multirow{2}{*}{\multicolumn{6}{|c|}{$\begin{array}{l}\text { CV }(\%)^{1}=22,03 \\
\text { CV }(\%)^{2}=26,16\end{array}$}} \\
\hline & & & & & \\
\hline & \multicolumn{5}{|c|}{ Microporosidade $\left(\mathrm{m}^{3} \mathrm{~m}^{-3}\right)$} \\
\hline $0-0,05$ & $0,257 \mathrm{Cbb}$ & $0,301 \mathrm{Ba}$ & $0,345 \mathrm{Aa}$ & $0,351 \mathrm{Aa}$ & $0,260 \mathrm{BCa}$ \\
\hline $0,05-0,10$ & $0,270 \mathrm{Cab}$ & $0,325 \mathrm{ABa}$ & $0,302 \mathrm{BCb}$ & $0,345 \mathrm{Aa}$ & $0,267 \mathrm{Ca}$ \\
\hline $0,10-0,20$ & $0,306 \mathrm{ABa}$ & $0,302 \mathrm{ABa}$ & $0,279 \mathrm{Bb}$ & $0,331 \mathrm{Aa}$ & $0,291 \mathrm{ABa}$ \\
\hline \multirow{2}{*}{\multicolumn{6}{|c|}{$\begin{array}{l}\text { CV }(\%)^{1}=16,57 \\
\text { CV }(\%)^{2}=17,31\end{array}$}} \\
\hline & & & & & \\
\hline \multicolumn{6}{|c|}{ Densidade do solo $\left(\mathrm{Mg} \mathrm{m}^{-3}\right)$} \\
\hline $0-0,05$ & $1,16 \mathrm{Cc}$ & $1,54 \mathrm{Bb}$ & $1,76 \mathrm{Aa}$ & $1,61 \mathrm{ABb}$ & $1,42 \mathrm{Bb}$ \\
\hline $0,05-0,10$ & $1,38 \mathrm{Bb}$ & $1,77 \mathrm{Aa}$ & $1,82 \mathrm{Aa}$ & $1,76 \mathrm{Aa}$ & $1,53 \mathrm{Bb}$ \\
\hline $0,10-0,20$ & $1,62 \mathrm{Aa}$ & $1,76 \mathrm{Aa}$ & $1,75 \mathrm{Aa}$ & $1,76 \mathrm{Aa}$ & $1,69 \mathrm{Aa}$ \\
\hline \multicolumn{6}{|c|}{ CV $(\%)^{1}=18,11$} \\
\hline CV $(\%)^{2}=14$ & & & & & \\
\hline
\end{tabular}

MN - mata nativa, SPD6 - sistema plantio direto com 6 anos, SPD8 - sistema plantio direto com 8 anos, SPD10 - sistema plantio direto com 10 anos e SPC - sistema de preparo convencional no Latossolo Vermelho. Médias seguidas da mesma letra maiúscula na linha e minúscula na coluna, em cada variável, não diferem entre si pelo teste de Tukey $(p<0,05)$. Coeficiente de variação referente aos tratamentos (parcelas) ${ }^{1}$ e Coeficiente de variação referente às camadas (subparcelas) ${ }^{2}$ camada de 0,075-0,125 m e maior microporosidade na camada de $0-0,025 \mathrm{~m}$ na semeadura direta, quando comparado com os demais sistemas enquanto a porosidade total variou de 0,36 a $0,51 \mathrm{~m}^{3} \mathrm{~m}^{-3}$ sem interferência dos sistemas de manejo em experimento conduzido por 17 anos, porém Bilibio et al. (2010) constataram que tanto no sistema convencional quanto no conservacionista (cultivo mínimo e plantio direto) de um Latossolo Vermelho distrófico, ocorreu compactação subsuperficial $(0,05-030 \mathrm{~m})$ indicada pela redução da relação macro/microporos, acompanhada pelo aumento da densidade do solo.

Nos manejos a variação da macroporosidade $(0,103$ a 0,267 $\mathrm{m}^{3} \mathrm{~m}^{-3}$ ) foi mais ampla, mas inferior numericamente em relação à microporosidade $\left(0,260 \mathrm{a} 0,351 \mathrm{~m}^{3} \mathrm{~m}^{-3}\right)$ e os maiores valores deste último foram verificados no SPD10 na camada de 0,05 0,20 m em comparação com o SPD8 pois, segundo Reichert et al. (2007) durante o processo de compactação do solo os poros maiores, responsáveis pela aeração do solo, diminuem e são substituídos por microporos. Na camada de 0-0,05 m do SPD8 e de 0,05-0,20 $\mathrm{m}$ do SPD10, a macroporosidade foi próxima a $0,10 \mathrm{~m}^{3} \mathrm{~m}^{-3}$, mínimo adequado para as trocas líquidas e gasosas entre o ambiente externo e o solo, e considerado crítico para o crescimento das raízes da maioria das culturas (Reichert et al., 2007). Torres et al. (2011) afirmaram, em Latossolo Vermelho, que em todos os sistemas de manejo estudados: preparo convencional (há mais de 20 anos), semeadura direta (há 9 anos), pastagem (há 4 anos) e campo nativo, os valores médios de volume de macroporos se apresentaram próximos ou superiores àquele considerado ideal $\left(0,33 \mathrm{dm}^{3} \mathrm{dm}^{-3}\right)$; entretanto e segundo esses mesmos autores, alguns valores abaixo de 0,33 $\mathrm{dm}^{3} \mathrm{dm}^{-3}$ na área de preparo convencional estavam relacionados ao revolvimento do solo na camada superficial $(0-0,05 \mathrm{~m})$ e ao pé de grade observado na camada mais profunda $(0,20-0,30 \mathrm{~m})$.

Os sistemas de plantio direto na camada de 0-0,20 m tiveram comportamento semelhante em relação à densidade do solo (Ds) com exceção da camada de 0-0,05 m em que o SPD6 foi inferior apenas ao SPD8 indicando, para este parâmetro, que o tempo de adoção de plantio direto não influenciou a Ds. A densidade do solo na camada $0-0,05 \mathrm{~m}$ do SPC foi significativamente menor em relação ao SPD8; de acordo com Silva et al. (2005b) maiores valores de densidade de solo na superfície do sistema plantio direto em relação ao SPC, são verificados em muitos casos e estão relacionados ao adensamento natural em função da ausência de revolvimento e também pela compactação ocasionada pelo tráfego de máquinas. Esses dados concordam com os de Mazurana et al. (2011) que, estudando a implicação que os sistemas de preparo de solo impõem sobre as características físicas de um Argissolo Vermelho, também observaram valores maiores de Ds na semeadura direta em que o revolvimento é menor e menores valores foram verificados nos sistemas de preparo com maior grau de mobilização do solo.

A tensão de água no solo em uma parte do ciclo do milho encontra-se abaixo da capacidade de campo (0,010 $\mathrm{MPa})$ durante o ciclo da cultura, o que pode ser verificado na Figura 2; nota-se que a $0,10 \mathrm{~m}$ de profundidade as tensões de água foram superiores às de 0,20 m, no SPD6 e o SPD8, durante a maior parte do ciclo da cultura e o SPD6 apresentou a menor diferença de tensões em comparação com as duas profundidades 


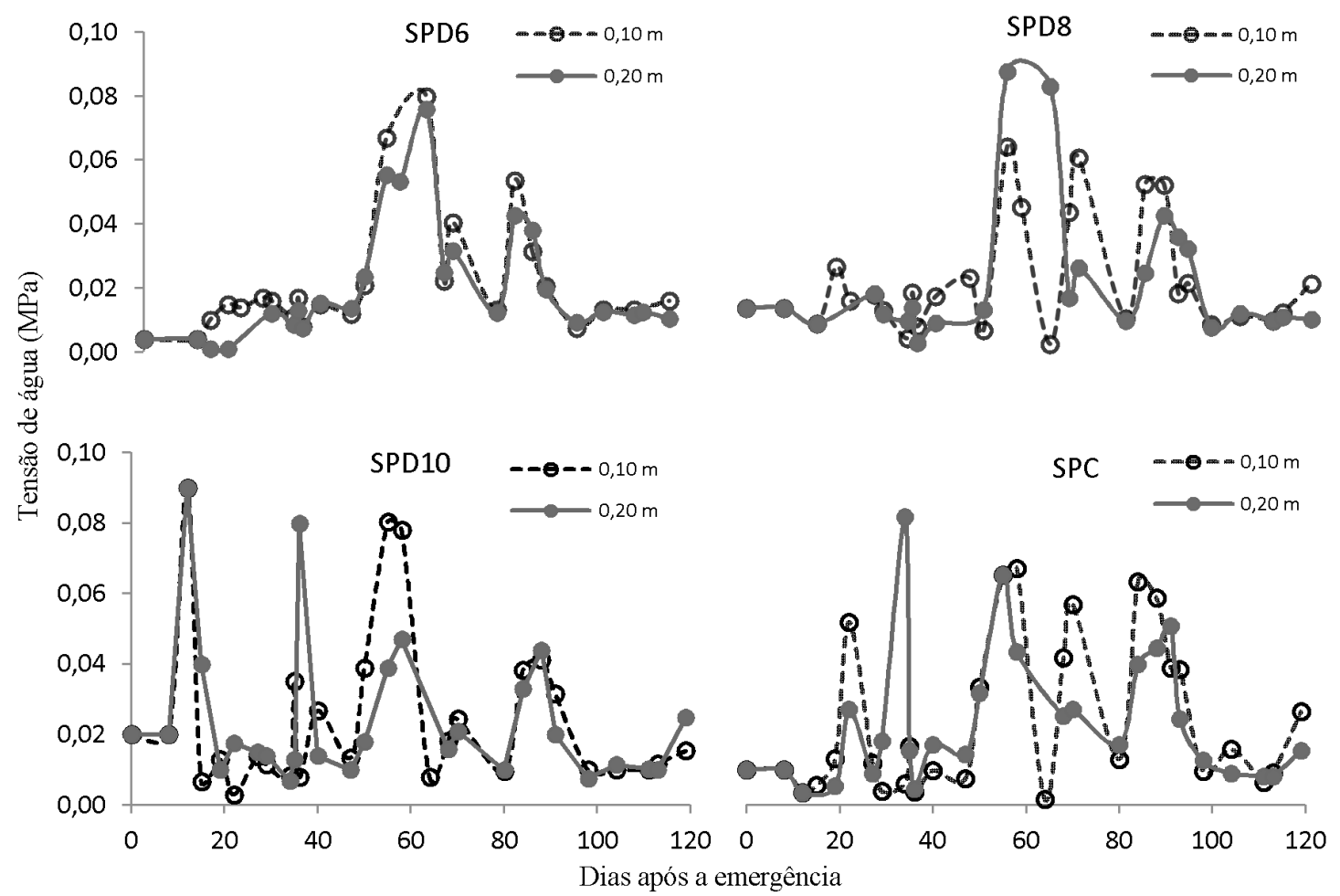

Figura 2. Variação da tensão de água no solo a 0,10 e 0,20 m de profundidade e de um Latossolo Vermelho sob diferentes sistemas de manejo (SPD, SPC), durante o ciclo da cultura do milho

em relação a todos os tratamentos. Observou-se que o SPD10 e o SPC apresentaram mais dias de altas tensões de água no solo durante o ciclo da cultura em comparação com o SPD6 e o SPD8, que restringiram este comportamento por volta de 50 a 70 dias após a emergência.

Mesmo com essa restrição de água no solo observada anteriormente, não se verificou diferença na condutividade hidráulica no solo entre o SPC e os tempos de adoção de plantio direto (Figura 3). Em Latossolo Vermelho-Amarelo Silva \& Kato (1997) constataram diferenças relevantes na condutividade hidráulica saturada do solo sob plantio direto e sob manejo convencional sinalizando que pequenas diferenças na macroporosidade foram acompanhadas por elevadas diferenças de valores de condutividade hidráulica. Nota-se também que em todos os tratamentos as tensões de água no solo foram inferiores a 0,09 $\mathrm{MPa}$ (Figura 2) e, desta forma, segundo Azevedo (2002), quando a tensão é superior a 0,04 a 0,06 MPa, pode limitar a absorção de água pela cultura do milho.

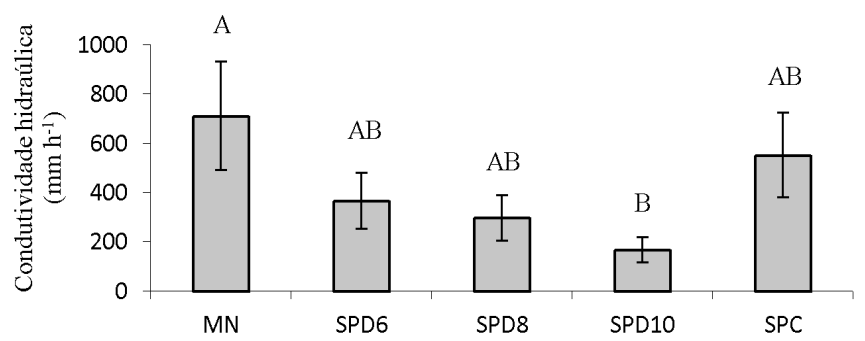

Médias seguidas da mesma letra não diferem estatisticamente pelo teste de Tukey $(p<0,05)$ (CV $=30,50 \%)$ e as barras se referem aos erros padrões das médias

Figura 3. Condutividade hidráulica de um Latossolo Vermelho na mata nativa (MN) e sob diferentes sistemas de manejo (SPD, SPC) até $0,15 \mathrm{~m}$ de profundidade
Maiores valores de condutividade hidráulica foram verificados no solo sob MN e este diferiu apenas do SPD10 (Figura 3) concordando, portanto, com os resultados obtidos por Stone et al. (2002), o que pode ser atribuído à maior quantidade de poros nesse último sistema. Os mesmos autores constataram que o efeito da compactação na redução do tamanho dos poros que transportam água, explica a redução da condutividade hidraúlica com o aumento da densidade do solo, contradizendo Castro et al. (2009) que concluíram que 8 anos de semeadura direta cultivada com milho permitiu uma condutividade hidráulica saturada maior, até $0,20 \mathrm{~m}$ de profundidade em Latossolo Vermelho, quando comparado com os sistemas de preparo mecânico (preparo escarificado e preparo convencional) devido à maior continuidade dos poros na semeadura direta.

A média da resistência mecânica do solo à penetração durante todo o ciclo da cultura do milho (Figura 4) para a camada de 0-0,05 m nos tratamentos SPD6, SPD10, SPD8 e $\mathrm{SPC}$, foi de 2,$81 ; 2,68 ; 1,96$ e $1,73 \mathrm{MPa}$, respectivamente; na camada de 0,10-0,20 m, para o SPD10, SPD6, SPD8 e SPC foi de 2,60; 2,07; 2,01 e 1,76 MPa, respectivamente; logo, a média da RP no SPD6 na camada de $0-0,05 \mathrm{~m}$ foi superior à dos demais tratamentos corroborando, desta maneira, com os valores de tensão de água (Figura 2) apresentados na camada superficial; todavia verificou-se, em resultados obtidos por Ralisch et al. (2008) maior resistência à penetração do Latossolo Vermelho-Amarelo no plantio direto há 8 anos $(2,80 \mathrm{MPa})$ e menor no preparo convencional $(0,70 \mathrm{MPa})$, na camada de 0,05 $\mathrm{m}$. As maiores tensões de água na camada de $0,10-0,20 \mathrm{~m}$ em determinados períodos durante o ciclo do milho foram no SPD8 $(0,087 \mathrm{MPa})$ e do SPD10 (0,09 e 0,08 MPa) e se converteram, provavelmente, em resistência à penetração no SPD8 $(5,65$ MPa) e SPD10 (6,13 e 5,67 MPa; portanto, esta condição de 


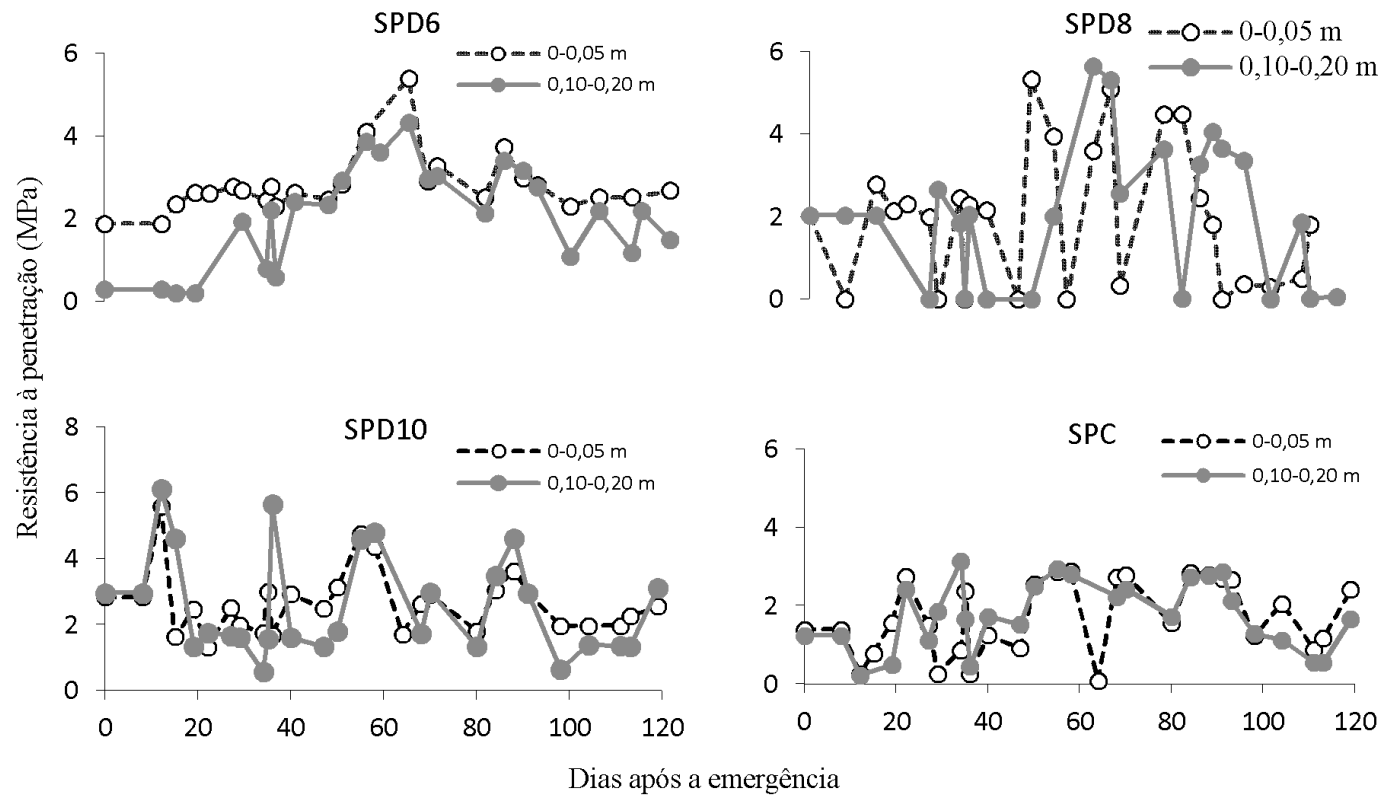

Figura 4. Variação da resistência mecânica à penetração do Latossolo Vermelho em função dos dias após a emergência durante o ciclo da cultura do milho

solo mais seco proporcionou, principalmente no SPD10, menor macroporosidade $\left(0,061 \mathrm{~m}^{3} \mathrm{~m}^{-3}\right)$.

A cultura do milho pode sofrer reduções na produção de grãos quando há déficit hídrico no período crítico da cultura, que ocorre desde o pendoamento até o início do enchimento dos grãos, ou seja, o período compreendido entre 60 e 80 dias após a emergência. Assim, pode-se observar, na Figura 4, que no período crítico a RP do SPD10 variou em torno de 1,5 a 3,0 MPa e a tensão de água no solo oscilou de 0,010 a $0,0244 \mathrm{MPa}$ (Figura 2) em comparação com os tratamentos com tempos de adoção de plantio direto. Em contrapartida e mesmo o SPD6 e o SPD8 terem apresentado uma RP superior em relação ao SPD10 neste período crítico, isto não influenciou a produtividade de grãos desses tratamentos (Figura 5).

Assim, os resultados desse ano agrícola discordam dos de Tormena et al. (1998), os quais afirmam que valores de RP acima de 2,0 MPa são considerados impeditivos para o crescimento de raízes em Latossolo Roxo. Valores de RP de 2,0 a 4,0 MPa, segundo Tavares Filho \& Tessier (2009) podem restringir, ou mesmo impedir, o crescimento e o desenvolvimento das raízes porém a compactação do solo é mais prejudicial em solo seco sendo que em condições de maior conteúdo de água pode haver crescimento radicular em valores de resistência do solo à penetração superiores a 4,0 MPa. Neste sentido, Lanzanova et al. (2010) encontraram menor resistência à penetração no Argissolo Vermelho descoberto até a camada de $0,03 \mathrm{~m}$ e o selamento superficial dos poros do solo ocasionou uma taxa de infiltração lenta de água em comparação com os cultivos sob semeadura direta.

O aumento da resistência mecânica do solo à penetração, causada pela diminuição do conteúdo de água no solo, restringiu todas as características avaliadas da cultura com exceção apenas do diâmetro do colmo (Tabela 4). A altura das plantas, o diâmetro do colmo, a altura de inserção da primeira espiga e a produtividade de milho, apresentaram comportamento linear decrescente com a resistência do solo à penetração submetida à tensão de 0,010 MPa na camada de 0-0,20 m (Figura 5) e atingiram até 2,0 MPa preconizado como crítico para a maioria das culturas (Tormena et al., 1998). Sendo assim, não se observa uma compactação acentuada que justifique alterações expressivas em relação às características das plantas. Valores semelhantes entre 0,90 e 2,00 MPa também foram observados por Freddi et al. (2006) em Latossolo Vermelho de textura argilosa e não reduziram a produtividade do milho.

É notório que os fatores que dificultam a obtenção de valores críticos ao desenvolvimento das culturas são acentuadamente influenciados pelo conteúdo de água, textura e pela condição estrutural do solo. Em virtude da RP estar diretamente relacionada à umidade do solo, tem sido difícil estabelecer, no campo, a RP crítica. Com o aumento da umidade a RP pode mudar rapidamente de uma provável condição limitante para outra não limitante.

O SPC (Figura 6) teve uma produtividade média inferior e diferiu estatisticamente apenas do SPD 10, porém não se observou tensão de água no solo (Figura 2) nem valores de resistência do solo

Tabela 4. Resumo da análise de variância para a altura das plantas, altura de inserção da primeira espiga, diâmetro do colmo e produtividade, em Latossolo Vermelho

\begin{tabular}{llcccc}
\hline Características da planta & Média & CV & Quadrado médio & Fc & Pr $>$ Fc \\
do resíduo & geral & (\%) & 0,008 & 13,14 & $<0,001$ \\
Altura das plantas $(\mathrm{m})$ & 2,43 & 3,77 & 0,0072 & 3,93 & 0,0235 \\
Alt. inserção $1^{\mathrm{a}}$ espiga $(\mathrm{m})$ & 1,09 & 7,74 & 0,0002 & 1,36 & 0,284 \\
Diâmetro do colmo $(\mathrm{m})$ & 0,0019 & 6,83 & 1,61 & 3,20 & 0,0456 \\
Produtividade $\left(\mathrm{t} \mathrm{ha}^{-1}\right)$ & 8,63 & 14,72 & & \\
\hline
\end{tabular}

$\mathrm{Fc}$ - valor do F calculado; $\mathrm{Pr}$ - probabilidade de se obter um valor de $\mathrm{F} \geq \mathrm{FC}$ 

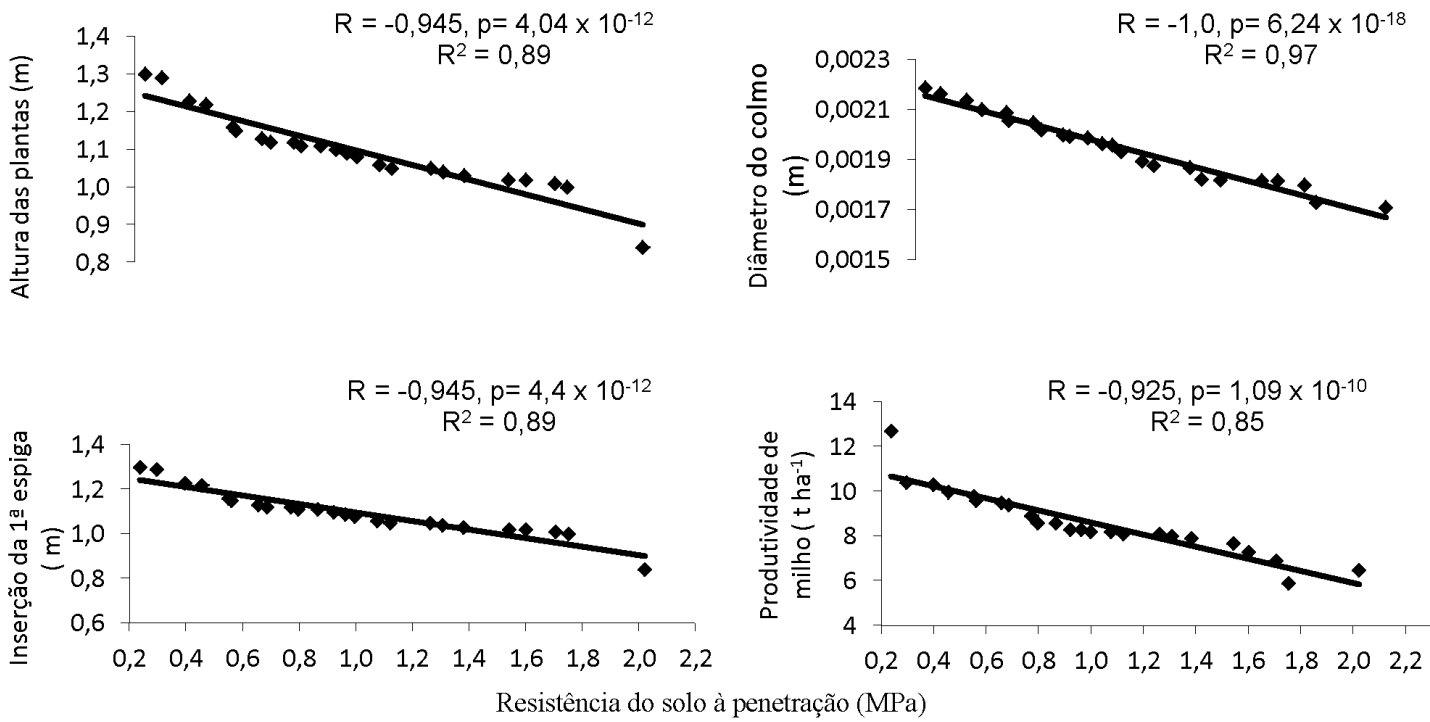

Figura 5. Regressão entre a resistência mecânica à penetração do Latossolo Vermelho 0,010 MPa e a altura das plantas, diâmetro do colmo, inserção da primeira espiga e produtividade de milho

à penetração impeditivos durante o ciclo da cultura; o que pode ter contribuído para a menor produtividade no SPC foi a perda de solo e nutrientes, devido à erosão hídrica. De acordo com Silva et al. (2005a), no sistema plantio direto, em média, as perdas de solo são menores que as observadas no preparo convencional em virtude, possivelmente, da cobertura oferecer proteção contra o impacto das gotas de chuva e, ainda, ao fato de o solo ser menos resistente ao escoamento em razão do preparo.

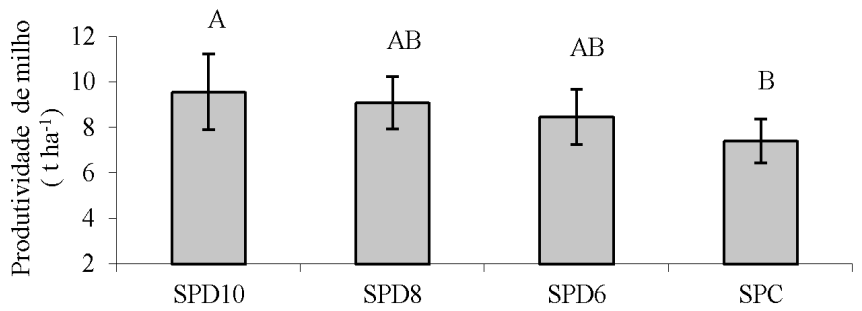

As barras se referem aos erros padrões das médias

Figura 6. Produtividade média de grãos de milho sob

diferentes sistemas de manejo em 2009/10

Debiasi et al. (2010) também verificaram, em Argissolo Vermelho, que a escarificação reduziu significativamente a produtividade do milho em relação ao sistema de plantio direto contínuo. Segundo os autores, tal fato pode ser associado aos valores excessivamente baixos de densidade do solo e altos de macroporosidade na área escarificada o que, provavelmente, reduziu a disponibilidade de água. Já neste estudo foram observados valores de macroporosidade superior no SPC em relação ao SPD10 apenas na camada de $0-0,10 \mathrm{~m}$ e não se verificaram valores de densidade do solo extremamente baixos em comparação com esses tratamentos, fato que pode ter contribuído para o comportamento semelhante desses em relação à condutividade hidráulica saturada do solo.

\section{CONCLUSÕES}

1. Os tratamentos apresentaram condições de resistência mecânica do solo à penetração, favoráveis ao cultivo até 0,20 m, já que o efeito da escarificação não comprometeu a estrutura do solo.

2. A altura das plantas, o diâmetro do colmo, a altura de inserção da primeira espiga e a produtividade de milho, apresentaram relação linear decrescente com a resistência mecânica do solo à penetração.

3. O sistema plantio direto de dez anos teve uma produtividade média superior e diferiu apenas do preparo convencional, porém este apresentou valores da média da resistência mecânica do solo à penetração inferiores em relação aos demais tratamentos.

4. A condutividade hidráulica saturada no solo mostrou comportamento semelhante entre o sistema de preparo convencional e os tempos de adoção de plantio direto.

\section{Agradecimentos}

À Fundação de Amparo à Pesquisa do Estado de São Paulo (FAPESP) pela concessão da bolsa de estudos.

\section{Literatura Citada}

Albuquerque, J. A.; Sangoi, L.; Ender, M. Efeitos da integração lavoura-pecuária nas propriedades físicas do solo e características da cultura do milho. Revista Brasileira de Ciência do Solo, v.25, p.717-723, 2001.

Andrioli, I.; Centurion, J. F. Levantamento detalhado dos solos da Faculdade de Ciências Agrárias e Veterinárias de Jaboticabal. In: Congresso Brasileiro de Ciênciado Solo, 27, 1999. Brasília. Anais...Campinas: SBCS, 1999. CD-Rom

Azevedo, J. A. Controle da irrigação para uso racional de água e de energia. Planaltina: MAPA, 2002. 4p. Comunicado Técnico, 83

Bilibio, W. D.; Corrêa, G. F.; Borges, E. N. Atributos físicos e químicos de um Latossolo, sob diferentes sistemas de cultivo. Ciência e Agrotecnologia, v.34, p.817-822, 2010. 
Blake, G. R.; Hartge, K. H. Particle density. In: Klute, A. Methods of soil analysis:physical and mineralogical methods. 2.ed. Madison: American Society of Agronomy, 1986. p.377-382.

Castro, O. M. de; Vieira, S. R.; Siqueira, G. M.; Andrade, C. A. de. Atributos físicos e químicos de um Latossolo Vermelho eutroférrico sob diferentes sistemas de preparo. Bragantia, v.68, p.1047-1057, 2009.

Danielson, R. E.; Sutherland, P. L. Porosity. In: Klute, A. Methods of soil analysis: Part 1- Physical and mineralogical methods. Madison: American Society of Agronomy, 1986. Part1, p.443-460.

Debiasi, H.; Levien, R.; Trein, C. R.; Conte, O. S.; Kamimura, K. M. Produtividade de soja e milho após coberturas de inverno e descompactação mecânica do solo. Pesquisa Agropecuária Brasileira, v.45, p.603-612, 2010.

Dexter, A. R.; Czyz, E. A.; Gat, O. P. A method for prediction of soil penetration resistance. Soil and Tillage Research, v.93, p.412-419, 2007.

EMBRAPA - Empresa Brasileira de Pesquisa Agropecuária. Centro Nacional de Pesquisas de Solos. Manual de métodos de análises de solo. Rio de Janeiro: Embrapa Solos, 1997. p.125-134.

Flores, C. A.; Reinert, D. J.; Reichert, J. M.; Albuquerque, J. A.; Pauletto, E. A. Recuperação da qualidade estrutural, pelo sistema plantio direto, de um Argissolo Vermelho. Ciência Rural, v.38, p.2164-2172, 2008.

Freddi, O. S.; Carvalho, M. P.; Veronesi Júnior, V.; Carvalho, G. J. Produtividade do milho relacionada com a resistência mecânica à penetração do solo sob preparo convencional. Engenharia Agrícola, v.26, p.113-121, 2006.

Klute, A. Water retention: Laboratory methods. In: Klute, A. Methods of soil analysis.Madison: American Society of Agronomy, 1986. Part. 1, p.635-662.

Lanzanova, M. E.; Eltz, F. L. F.; Nicoloso, R.; Amado, T. J. C.; Reinert, D. J.; Rocha, M. R. da. Atributos físicos de um argissolo em sistemas de culturas de longa duração sob semeadura direta. Revista Brasileira de Ciência do Solo, v.34, p.1333-1342,2010.

Machado, J. L.; Tormena, C. A.; Fidalski, J.; Scapim, C. A. Inter-relações entre as propiedades físicas e os coeficientes da curva de retenção de água de um Latossolo sob diferentes sistemas de uso. Revista Brasileira de Ciência do Solo, v.32, p.495-502,2008.

Mazurana, M.; Levien, R.; Müller, J.; Conte, O. Sistemas de preparo de solo: alterações na estrutura do solo e rendimento das culturas. Revista Brasileira de Ciência do Solo, v.35, p.1197-1206,2011.

Raij, B. van; Andrade, J. C.; Cantarella, H.; Quaggio, J. A. Análise química para avaliação da fertilidade de solos tropicais. Campinas: Instituto Agronômico, 2001. 285p.
Ralisch, R.; Miranda, T. M.; Okumura, R. S.; Barbosa, G. M. de C.; Guimarães, M. de F.; Scopel, E.; Balbino, L. C. Resistência à penetração de um Latossolo Vermelho Amarelo do cerrado sob diferentes sistemas de manejo. Revista Brasileira de Engenharia Agrícola e Ambiental, v.12, p.381-384, 2008.

Reichardt, K.; Timm, L. C. Solo, planta e atmosfera: Conceitos, processos e aplicações. 2.ed. Barueri: Manole, 2012. 524p.

Reichert, J. M.; Suzuki, L. E. A. S.; Reinert, D. J. Compactação do solo em sistemas agropecuários e florestais: Identificação, efeitos, limites críticos e mitigação. In: Ceretta, C.A.; Silva, L. S.; Reichert, J. M. (ed.) Tópicos em ciência do solo. 5.ed. Viçosa: SBCS, 2007. p.49-134.

Silva, C. G.; Alves Sobrinho, T.; Vitorino, A. C. T.; Carvalho, D. F. Atributos físicos, químicos e erosão entressulcos sob chuva simulada, em sistemas de plantio direto e convencional. Engenharia Agrícola, v.25, p.144-153, 2005a.

Silva, C. L.; Kato, E. Efeitos do selamento superficial na condutividade hidráulica saturada da superfície de um solo sob cerrado. Pesquisa Agropecuária Brasileira, v.32, p.213-220, 1997.

Silva, M. A. S. da; Mafra, Á. L.; Albuquerque, J. A.; Bayer, C.; Mielniczuk, J. Atributos físicos do solo relacionados ao armazenamento de água em um Argissolo Vermelho sob diferentes sistemas de preparo. Ciência Rural, v.35, p.544-552, 2005 b.

Silva, M. A. S. da.; Mafra, Á. L.; Albuquerque, J. A.; Rosa, J. D.; Bayer, C.; Mielniczuk, J. Propriedades físicas e teor de carbono orgânico de um Argissolo Vermelho sob distintos sistemas de uso e manejo. Revista Brasileira de Ciência do Solo, v.30, p.329-337,2006.

Souza, Z. M. de; Campos, M. C. C.; Cavalcante, I. H. L.; Marques Júnior, J.; Cesarin, L. G.; Souza, S. R. de. Dependência espacial da resistência do solo à penetração e do teor de água no solo sob cultivo contínuo de cana-deaçúcar. Ciência Rural, v.36, p.128-134, 2006.

Stone, L. F.; Guimaraes, C. M.; Moreira, J. A. A. Compactação do solo na cultura do feijoeiro. I: efeitos nas propriedades físico-hídricas do solo. Revista Brasileira de Engenharia Agrícola e Ambiental, v.6, p.207-212, 2002.

Tavares Filho, J.; Ribon, A. A. Resistência do solo à penetração em resposta ao número de amostras e tipo de amostragem. Revista Brasileira de Ciência do Solo, v.32, p.487-494, 2008.

Tavares Filho, J.; Tessier, D. Compressibility of oxisol aggregate sunder no-till in response to soil water potential. Revista Brasileira de Ciência do Solo, v.33, p.1525-1533, 2009.

Tormena, C. A.; Silva, A. P.; Libardi, P. L. Caracterização do intervalo hídrico ótimo de um Latossolo Roxo sob plantio direto.Revista Brasileira de Ciência do Solo, v.22, p.573581,1998 .

Torres, J. L. R.; Fabian, A. J.; Pereira, M. G. Alterações dos atributos físicos de um Latossolo Vermelho submetido a diferentes sistemas de manejo. Ciência e Agrotecnologia, v.35, p.437-445, 2011. 